06;07

\title{
Изучение характеристик транзисторов на гетероструктурах нитрида галлия, выращенных методом аммиачной молекулярно-лучевой эпитаксии на подложках сапфира и кремния
}

\author{
(С) А.А. Андреев, Ю.В. Грищенко, И.С. Езубченко, М.Я. Черных, Е.М. Колобкова, И.О. Майборода, \\ И.А. Черных, М.Л. Занавескин
}

Национальный исследовательский центр „Курчатовский институт“, Москва, Россия

E-mail: andreev_aa@nrcki.ru

Поступило в Редакцию 22 октября 2018 г.

В окончательной редакции 26 ноября 2018 г.

Принято к публикации 28 ноября 2018 г.

Методом аммиачной молекулярно-лучевой эпитаксии выращены нитридные гетероструктуры на подложках сапфира и кремния. На их основе созданы транзисторы с периферией $1.2 \mathrm{~mm}$. Транзисторы на подложках обоих типов демонстрируют схожие высокие статические характеристики: ток насыщения более $0.75 \mathrm{~A} / \mathrm{mm}$, крутизна более $300 \mathrm{mS} / \mathrm{mm}$, напряжение пробоя выше $120 \mathrm{~V}$. Измерения малосигнальных параметров свидетельствуют о большей величине усиления транзисторов на подложках кремния в диапазоне до $5 \mathrm{GHz}$. Удельная мощность на частоте $1 \mathrm{GHz}$ составляет для транзисторов на подложке сапфира $5 \mathrm{~W} / \mathrm{mm}$, на подложке кремния - $2 \mathrm{~W} / \mathrm{mm}$.

DOI: $10.21883 /$ PJTF.2019.04.47340.17567

В последнее десятилетие интенсивное развитие получили технологии роста нитрид-галлиевых гетероструктур на кремниевых подложках и создания HEMT (high electron mobility transistor) на их основе ( $\mathrm{GaN}-\mathrm{on}-\mathrm{Si})[1,2]$. Интерес к технологиям $\mathrm{GaN}-$ on-Si связан с возможностью реализации постростового процессинга гетероструктур на существующих кремниевых фабриках. Это позволяет значительно удешевить процесс создания устройств на основе нитрид-галлиевых гетероструктур.

Однако из-за большого рассогласования параметров кристаллических решеток и коэффициентов термического расширения между нитридными соединениями и подложкой кремния в структуре возникают механические напряжения, которые приводят к растрескиванию нитрида галлия. Это делает задачу роста гетероструктур приборного качества на подложках кремния существенно более сложной, чем на подложках сапфира и карбида кремния.

Несмотря на перспективы, которые открывает использование HEMT GaN на $\mathrm{Si}$, в нашей стране подобные разработки представлены двумя публикациями $[3,4]$. Авторы работ сообщили о создании тестовых НЕМТ с шириной затвора 20 [3] и $100 \mu \mathrm{m}$ [4] на собственных гетероструктурах. При этом данные об измерениях сверхвысокочастотных (СВЧ) малосигнальных и мощностных параметров в указанных публикациях не приводились.

Цель настоящей работы состоит в создании архитектурно идентичных нитридных гетероструктур на кремнии и сапфире методом аммиачной молекулярнолучевой эпитаксии (МЛЭ), формировании мощных СВЧ-транзисторов с периферией $1.2 \mathrm{~mm}$ и проведении комплексных сравнительных исследований статических и СВЧ-характеристик полученных транзисторов.

Эпитаксиальные гетероструктуры были сформированы методом аммиачной МЛЭ в установке SemiTEQ STE3N. Структура буферных слоев и особенности роста на подложках сапфира $\left(c-\mathrm{Al}_{2} \mathrm{O}_{3}\right)$ приведены в работе [5]. Для обеих гетероструктур барьерный слой включал спейсер-слой $\mathrm{AlN}$ толщиной $1 \mathrm{~nm}$ и слой $\mathrm{Al}_{0.4} \mathrm{Ga}_{0.6} \mathrm{~N}$ толщиной $6 \mathrm{~nm}$.

Гетероструктура на кремнии ( $\mathrm{Si}(111), n$-тип, $\rho>10000 \Omega \cdot \mathrm{cm})$ была аналогична структуре на сапфире, за исключением начальных стадий роста, которые были оптимизированы в соответствии со спецификой эпитаксии нитридов на кремниевых подложках [6]. Перед началом роста подложки подвергались стандартной процедуре химической очистки, включающей травление в буферном растворе HF (разбавление 1:10) в течение 30 s. После сушки в струе азота подложки сразу переносились в ростовую установку. В ростовой камере подложка кремния подвергалась отжигу и нитридизации в потоке аммиака. Далее при $600^{\circ} \mathrm{C}$ проводилось осаждение двух монослоев Al. Затем при $800^{\circ} \mathrm{C}$ осаждался зародышевый слой $\mathrm{AlN}$ толщиной $5 \mathrm{~nm}$. Далее процесс был идентичен процессу на сапфировой подложке.

Невжигаемые омические контакты формировались путем рецесса гетероструктуры под контактом плазмохимическим травлением с последующей селективной эпитаксией слоя сильно легированного кремнием $\mathrm{GaN}$ в установке МЛЭ [7]. Межприборная изоляция транзисторов формировалась травлением в плазме $\mathrm{Cl}_{2} / \mathrm{BCl}_{3}$. Далее выполнялась металлизация невжигаемых контактов: $\mathrm{Cr}(40 \mathrm{~nm}) / \mathrm{Au}(300 \mathrm{~nm})$. Следующим этапом было формирование грибообразного затвора Шоттки длиной 


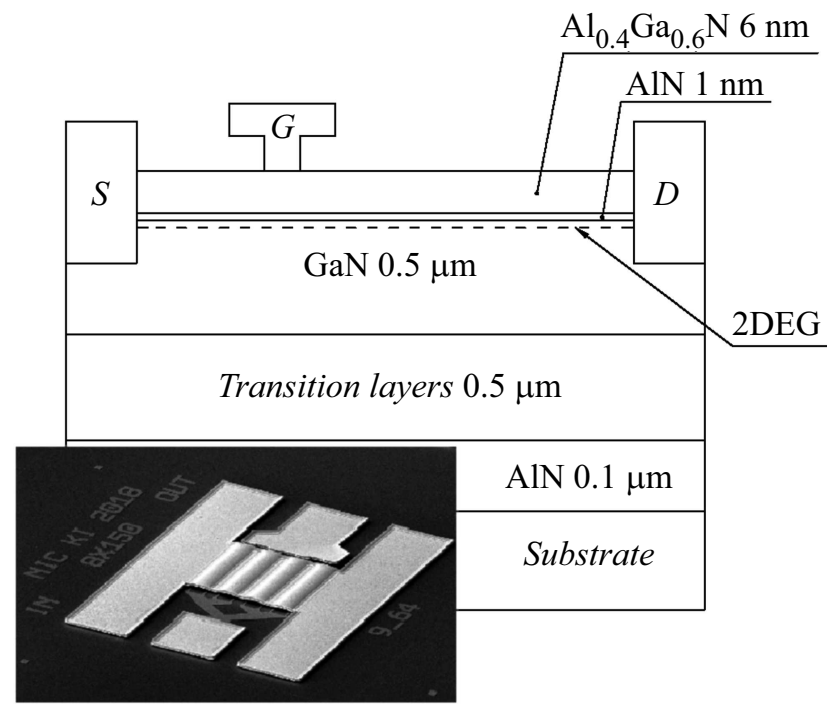

Рис. 1. Схема приборных структур, изучаемых в настоящей работе. $S$ - исток, $G$ - затвор, $D-$ сток, 2DEG двумерный электронный газ. На вставке - полученное с помощью растрового электронного микроскопа изображение НЕМТ с периферией $1.2 \mathrm{~mm}$.

$0.5 \mu \mathrm{m}$ : металлизация $\mathrm{Ni}(40 \mathrm{~nm}) / \mathrm{Au}(500 \mathrm{~nm})$. Слой пассивации $\mathrm{Si}_{3} \mathrm{~N}_{4}$ толщиной $50 \mathrm{~nm}$ формировался методом плазмохимического осаждения. Воздушные мосты формировались с помощью гальванического осаждения золота.

Топология транзисторов реализована в многопальцевой схеме $(8 \times 150 \mu \mathrm{m})$ с расстоянием исток-сток $4 \mu \mathrm{m}$ (рис. 1) и разработана с учетом возможности проведения СВЧ-измерений. Суммарная ширина затворов транзистора $1.2 \mathrm{~mm}$. Измерения статических параметров проводились на зондовой станции Cascade PM5 с помощью двухканального источника-измерителя Keithley 2636B при комнатной температуре. Измерения малосигнальных СВЧ-характеристик осуществлялись на зондовой станции с зондами $Z$-probe $67 \mathrm{GHz}$ и сетевом анализаторе Agilent E8361C. Мощностные характеристики измерялись с помощью векторного анализатора Agilent PNA E8361А в импульсном режиме с длиной импульса $1 \mu \mathrm{s}$ и периодом измерений $100 \mu \mathrm{s}$.

Из-за рассогласования параметров решеток подложки и эпитаксиальных слоев гетероструктура на кремнии имела большее число структурных дефектов. В результате, как и предполагается теоретическими моделями [8], транзисторы на кремнии обладали меньшей величиной начального тока насыщения $(550 \mathrm{~mA} / \mathrm{mm})$ и крутизной $(290 \mathrm{mS} / \mathrm{mm})$ при напряжении затвор-исток $U_{g s}=-1.3 \mathrm{~V}$. На подложке сапфира начальный ток насыщения составил $620 \mathrm{~mA} / \mathrm{mm}$, а максимальная крутизна $-380 \mathrm{mS} / \mathrm{mm}\left(U_{g s}=-1.7 \mathrm{~V}\right)$.

С другой стороны, более высокая теплопроводность подложки кремния способствовала меньшему разогреву транзисторов на ней, и при положительном напря- жении на затворах $\left(V_{g}=2 \mathrm{~V}, V_{d s}=10 \mathrm{~V}\right)$ транзисторы на кремниевой подложке показали большее значение максимального тока стока $\left(I_{d \max }\right)$, измеренного в непрерывном режиме. На кремнии он составил $870 \mathrm{~mA} / \mathrm{mm}$ (рис. $2, a$ ), а на сапфире $-770 \mathrm{~mA} / \mathrm{mm}$. Также при меньшей максимальной крутизне транзисторов на кремнии за счет лучшего теплоотвода коэффициент усиления в них обладает более высокой линейностью в широком диапазоне напряжений на затворе [9].

Пробивное напряжение транзистора на кремнии, измеренное трехзондовым методом, составило $140 \mathrm{~V}$ (рис. $2, b)$. Зависимость тока затвора от напряжения на стоке является монотонной, в то время как ток стока значительно увеличивается при напряжениях выше $120 \mathrm{~V}$. Затворная утечка транзистора после снятия пробного напряжения вернулась к своему значению до испытаний $60 \mu \mathrm{A}$, что свидетельствует об отсутствии пробоя по затвору. Отсутствие следов выгорания транзистора может указывать на механизм электрического пробоя через буферный слой во второй канал, расположенный, как мы предполагаем, на границе нитридной гетероструктуры и подложки кремния. Пробивное напряжение
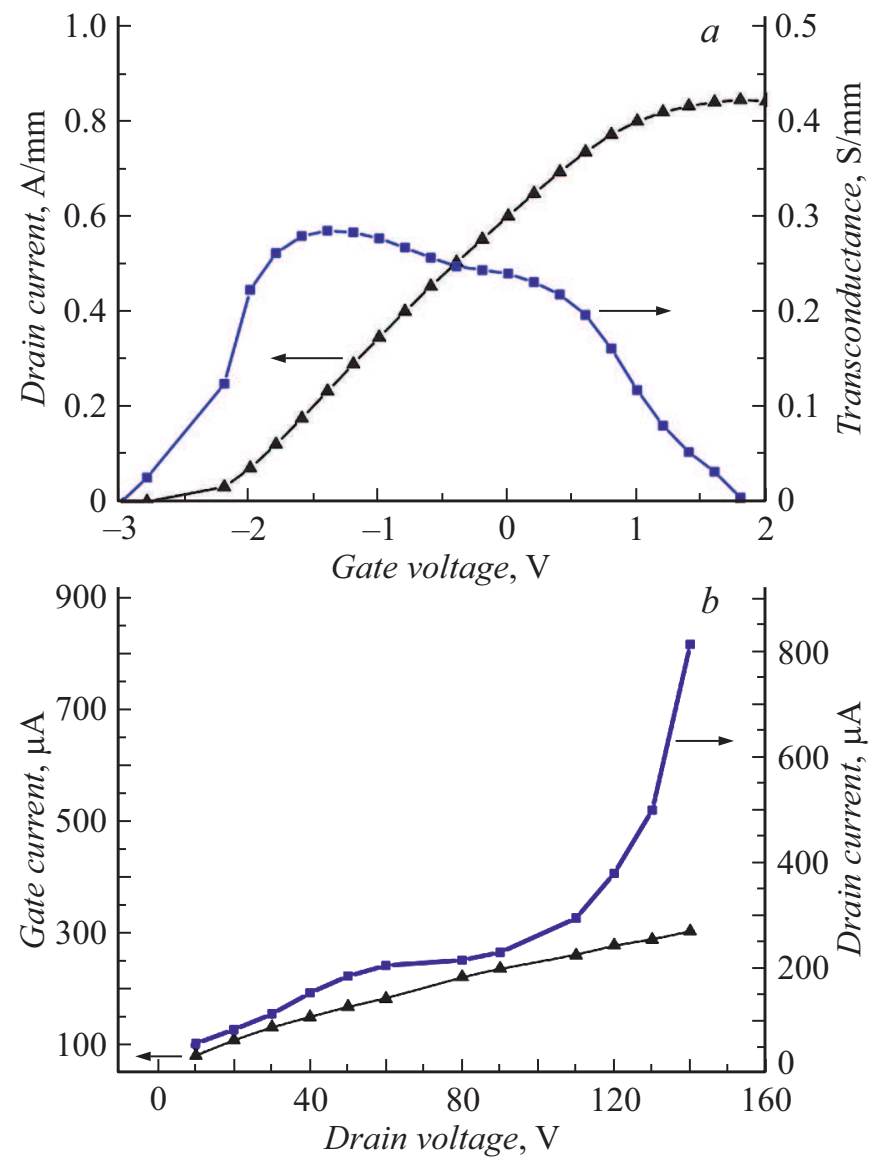

Рис. 2. $a-$ передаточная характеристика для транзистора с периферией $1.2 \mathrm{~mm}$ на кремниевой подложке при $U_{d s}=6 \mathrm{~V}$. $b$ - зависимости токов стока и затвора от напряжения сток-исток при $V_{g}=-7 \mathrm{~V}$. Ток стока и ток затвора регистрировались одновременно. 


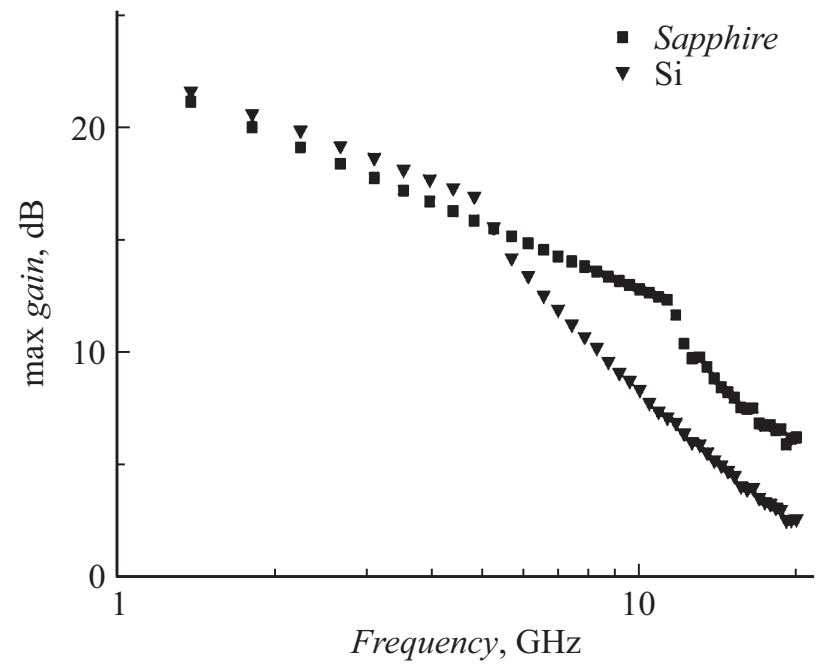

Рис. 3. Малосигнальные СВЧ-параметры транзисторов на подложках кремния и сапфира. Напряжение смещения сток-исток $10 \mathrm{~V}$.

для транзисторов на подложке сапфира составило более $140 \mathrm{~V}$, при этом пробой происходил от затвора в канал двумерного газа, что является типичным механизмом пробоя для высокочастотных НЕМТ.

На рис. 3 приведены измерения малосигнальных параметров транзисторов. Как видно, положение точки $K$ (переход MSG (maximum stable gain) в MAG (maximum available gain)) для транзисторов на кремниевой подложке находится на частоте $5 \mathrm{GHz}$, для подложки сапфира на частоте $11.5 \mathrm{GHz}$. Коэффициенты усиления по мощности на частоте $4.8 \mathrm{GHz}$ составили $17 \mathrm{~dB}$ на кремнии и $15.8 \mathrm{~dB}$ на сапфире. Выходная мощность транзисторов измерялась в импульсном режиме на частоте $1 \mathrm{GHz}$ при питании $20 \mathrm{~V}$. На подложке сапфира выходная мощность составила $5 \mathrm{~W} / \mathrm{mm}$, на подложке кремния $-2 \mathrm{~W} / \mathrm{mm}$.

Низкое значение коэффициента усиления при частотах выше $5 \mathrm{GHz}$ и меньшая выходная мощность транзисторов на кремнии наиболее вероятно связаны с наличием проводящего канала на интерфейсе $\mathrm{AlN} / \mathrm{Si}$ [10-12], который увеличивает паразитную емкость контактных площадок затвора и стока. Данная проблема является типичной для гетероструктур нитридов на кремнии и может быть решена путем оптимизации процесса формирования начальных эпитаксиальных слоев.

Таким образом, методом аммиачной МЛЭ выращены НЕМТ-гетероструктуры и на их основе созданы транзисторы на подложках кремния с периферией $1.2 \mathrm{~mm}$. Статические характеристики транзисторов находятся на уровне результатов, полученных при применении подложек сапфира и карбида кремния. Измеренная выходная мощность на частоте $1 \mathrm{GHz}$ составляет $2 \mathrm{~W} / \mathrm{mm}$ ( $5 \mathrm{~W} / \mathrm{mm}$ на сапфире). Значительное ухудшение малосигнальных и мощностных параметров, по всей видимости, обусловлено наличием паразитного канала на гетерогранице $\mathrm{AlN} / \mathrm{Si}$, что находится в корреляции с литера- турными данными. Определение природы образования паразитного канала в гетероструктурах нитрида галлия, выращенных методом МЛЭ на кремнии, разработка и поиск подходов для его устранения с целью улучшения частотных характеристик транзисторов на кремнии являются предметом дальнейших исследований.

Работа выполнена при поддержке НИЦ „Курчатовский институт“ (приказ от 23.08.2017 г. № 1383).

\section{Список литературы}

[1] Ganguly S., Song B., Hwang W.S., Hu Z., Zhu M., Verma J., Xing H., Jena D. // Phys. Status Solidi C. 2014. V. 11. N 3-4. P. $887-889$.

[2] Eblabla A., Li X., Thayne I., Wallis D.J., Guiney I., Elgaid K. // IEEE Electron Dev. Lett. 2015. V. 36. N 9. P. 899-901.

[3] Алексеев А.Н., Александров С.Б., Бырназ А.Э., Великовский Л.Э., Великовский И.Э., Красовицкий Д.М., Павленко М.В., Петров С.И., Погорельский М.Ю., Погорельский Ю.В., Соколов И.А., Соколов М.А., Степанов М.В., Ткаченко А.Г., Шкурко А.П., Чалый В.П. // Письма в ЖТФ. 2008. T. 34. B. 7. C. 58-64.

[4] Арендаренко А.А., Орешкин В.А., Свешников Ю.Н., Цыпленков И.Н. // Изв. вузов. Материалы электронной техники. 2015. Т. 18. № 1. С. 5-15.

[5] Lev L.L., Maiboroda I.O., Husanu M.A., Grichuk E.S., Chumakov N.K., Ezubchenko I.S., Chernykh I.A., Wang X., Tobler B., Schmitt T., Zanaveskin M.L., Valeyev V.G., Strocov V.N. // Nature Commun. 2018. V. 9. P. 2653 (1-9).

[6] LeLouarn A., Vezian S., Semond F., Massies J. // J. Cryst. Growth. 2009. V. 311. P. 3278-3284.

[7] Майборода И.О., Андреев А.А., Перминов П.А., Федоров Ю.В., Занавескин М.Л. // Письма в ЖТФ. 2014. Т. 40. B. 11 . C. $80-86$.

[8] Marino F.A, Faralli N., Palacios T., Ferry D.K., Goodnick S.M., Saraniti M. // IEEE Transact. Electron Dev. 2010. V. 57. N 1. P. 353-360.

[9] Chen C.H., Sadler R., Wang D., Hou D., Yang Y., Yau W., Sutton W., Shim J., Wang S., Duong A. // Solid-State Electron. 2016. V. 126. P. 115-124.

[10] Yacoub H., Fahle D., Finken M., Hahn H., Blumberg C., Prost W., Kalisch H., Heuken M., Vescan A. // Semicond. Sci. Technol. 2014. V. 29. N 11. P. 115012 (1-6).

[11] Rajagopal P., Roberts J.C., Cook J.W., Jr., Brown J.D., Piner E.L., Linthicum K.J. // Mater. Res. Soc. Symp. Proc. 2004. V. 798. P. Y7.2 (1-6).

[12] Chandrasekar H., Bhat K.N., Rangarajan M., Raghavan S., Bhat N. // Sci. Rep. 2017. V. 7. P. 15749 (1-10). 